EXTENDED REPORT

\title{
Laser photocoagulation for radiation retinopathy after ophthalmic plaque radiation therapy
}

\section{P T Finger, M Kurli}

Br J Ophthalmol 2005;89:730-738. doi: 10.1136/bjo.2004.052159

See end of article for authors' affiliations .....................

Correspondence to: Paul T Finger, The New York Eye Cancer Center, 115 East 61 st Street, New York City, NY 10021 USA; pfinger@ eyecancer.com

Accepted for publication 20 September 2004

\begin{abstract}
Aim: To evaluate the use of scatter laser photocoagulation to prevent radiation related retinopathy, maculopathy, and loss of vision.

Methods: This was an interventional case series. 66 eyes with posterior choroidal melanomas treated by ophthalmic plaque radiation therapy were reported. Of these patients, 50 were selected because they developed radiation retinopathy; 45 of these were treated with sector scatter laser photocoagulation to regress clinically evident radiation retinopathy. 16 additional patients (considered to be "high risk" to develop radiation retinopathy) were also treated.

Results: Radiation retinopathy was noted to appear at a mean interval of 26 months following plaque treatment. Laser photocoagulation regressed radiation retinopathy in $29(64.4 \%)$ of the 45 patients treated after the onset of radiation retinopathy (17 with only retinopathy, 10 with a combination of retinopathy and maculopathy, and two with only maculopathy). Of the 16 patients who received laser treatment before clinical evidence of retinopathy, one developed radiation maculopathy and two retinopathy without maculopathy (all three responded to additional laser photocoagulation). In the 45 patient group, vision loss of more than three lines was attributable to radiation maculopathy in seven (15.5\%). None of the patients in the prophylactic laser group lost more than three lines of vision as a result of maculopathy. Conclusion: Sector scatter argon laser photocoagulation induced regression of radiation retinopathy. Though early treatment of radiation retinopathy appears to be more effective, a more long term and prospective randomised study will be needed to prove efficacy.
\end{abstract}

$\mathrm{R}$ diation continues to have a crucial role in the treatment of ocular tumours. ${ }^{1}$ Unfortunately, secondary radiation associated keratopathy, cataract, glaucoma, vitreous haemorrhage, retinal detachment, chorioretinopathy, and optic neuropathy are reported vision limiting complications. ${ }^{2-6}$ Of these, radiation maculopathy is the most common cause of irreversible loss of central vision and blindness. Specifically, radiation therapy for choroidal melanoma has resulted in less than $20 / 200$ vision in over $50 \%$ of patients ( 5 year follow up). ${ }^{267}$

In 1981, Chaudhuri et al reported a case of radiation retinopathy with secondary retinal and optic nerve neovascularisation that was successfully palliated with panretinal photocoagulation. ${ }^{8}$ Then, in 1988, Augsburger et al found that panretinal photocoagulation was helpful to preserve eyes with "ocular ischaemia" secondary to cobalt-60 plaque radiation. ' In 1997, Finger suggested that treating the irradiated zone with scatter laser photocoagulation was adequate to induce regression of plaque associated radiation retinopathy. ${ }^{2}$

Prospective randomised evidence that scatter laser photocoagulation can preserve vision in patients with regional retinal ischaemia has been provided by the Branch Retinal Vein Occlusion (BRVO) Study. This study showed that laser treatment of ischaemic retina caused by a branch vein occlusion decreased the probability of vision loss (due to macular oedema and vitreous haemorrhage). ${ }^{10}$

We describe an interventional case series of patients treated with sector scatter laser photocoagulation to prevent progression of radiation retinopathy. We describe our methods of plaque brachytherapy, radiation dosimetry, laser photocoagulation, the incidence of retinopathy, and preservation of vision.

\section{METHODS}

Sixty six patients with posterior choroidal melanoma were included in this study (table 1). At the time of melanoma diagnosis, each patient participated in a detailed discussion of the risks and benefits of observation, radiation, and enucleation as it related to their tumour's size, location, and risk of metastasis. ${ }^{211}{ }^{12}$ Each patient chose to undergo plaque radiation therapy (table 2 ).

After plaque irradiation, 50 patients developed radiation retinopathy and were offered sector laser photocoagulation (table 3 ). In this group, the mean follow up (since plaque treatment) was 72.6 months. The mean onset from irradiation to retinopathy was 25.9 months. In all, 45 of the 50 were treated. This required a mean 2.75 (range 1-9) laser sessions per eye (table 3 ). The mean follow up after their initial laser treatment has been 48 months (table 4 ).

All patients treated with laser photocoagulation underwent a detailed discussion of the risks and potential benefits of therapy. At applicable, each patient signed a treatment consent and HIPAA (Health Insurance Portability and Accountability Act of 1996) form. The 45 patient group consisted of consecutive patients, whose retinas displayed signs of radiation retinopathy and who were willing to be treated by laser photocoagulation.

\section{High risk patients}

In 2000, we reported that choroidal melanomas centred posterior to the equator were at relatively high risk for radiation maculopathy and loss of central vision. ${ }^{12}$ Since

Abbreviations: $A R M D$, age related macular degeneration; BDR, background diabetic retinopathy; BRVO, branch retinal vein occlusion; $D M$, diabetes mellitus; HTN, hypertension; RR, radiation retinopathy 


\begin{tabular}{|c|c|c|c|c|c|c|c|c|c|c|c|}
\hline \multirow{2}{*}{$\frac{\text { Patient No }}{\text { Laser group }}$} & \multirow[b]{2}{*}{ Age } & \multirow[b]{2}{*}{ Sex } & \multirow[b]{2}{*}{ DM } & \multirow[b]{2}{*}{ HTN } & \multirow{2}{*}{$\begin{array}{l}\text { Additional ocular } \\
\text { disease }\end{array}$} & \multirow{2}{*}{ Eye } & \multirow{2}{*}{$\begin{array}{l}\text { Tumour } \\
\text { location }\end{array}$} & \multicolumn{3}{|c|}{ Size (mm) } & \multirow[b]{2}{*}{ TNM } \\
\hline & & & & & & & & Length & Width & Height & \\
\hline \multicolumn{12}{|c|}{ With retinopathy } \\
\hline 1 & 63 & $\mathrm{~F}$ & - & Y & - & RE & 530EP & 12 & 9 & 2.8 & T2NOMO \\
\hline 2 & 72 & M & - & - & Glaucoma & $\mathrm{LE}$ & 230EP & 9 & 10 & 4.9 & T2NOMO \\
\hline 3 & 84 & M & - & - & - & LE & 3ЕР & 10 & 12 & 4.2 & T2NOMO \\
\hline 4 & 52 & M & - & - & - & RE & 9EP & 10.3 & 11 & 5.3 & T2NOMO \\
\hline 5 & 56 & $\mathrm{~F}$ & - & - & - & RE & IEP & 7 & 8 & 2.4 & TINOMO \\
\hline 6 & 81 & $\mathrm{~F}$ & - & - & - & RE & 9EP & 7 & 12 & 3.6 & T2NOMO \\
\hline 7 & 67 & M & - & Y & - & LE & $230 \mathrm{E}$ & 14 & 12.5 & 6.5 & T2NOMO \\
\hline 8 & 86 & M & - & - & - & LE & $11 \mathrm{E}$ & 10 & 12 & 6.2 & T2NOMO \\
\hline 9 & 84 & $\mathrm{~F}$ & - & - & - & LE & 430ЕP & 6 & 8 & 4.4 & TINOMO \\
\hline 10 & 86 & M & - & Y & ARMD & RE & 1030EP & 12 & 10 & 2.9 & T2NOMO \\
\hline 11 & 34 & $\mathrm{~F}$ & - & - & - & RE & IPE & 5 & 6 & 1.9 & TINOMO \\
\hline 12 & 72 & M & Y & Y & BDR & LE & $3 E P$ & 14 & 16 & 3.4 & T2NOMO \\
\hline 13 & 86 & $\mathrm{~F}$ & - & Y & - & RE & 1030EP & 14 & 15 & 5.2 & T2NOMO \\
\hline 14 & 72 & M & Y & - & - & LE & 230EP & 10 & 10 & 3.4 & T2NOMO \\
\hline 15 & 58 & $\mathrm{~F}$ & - & - & - & LE & $1 \mathrm{P}$ & 7 & 10 & 3.2 & T2NOMO \\
\hline 16 & 81 & M & Y & - & - & RE & $230 \mathrm{P}$ & 8 & 10 & 4.1 & T2NOMO \\
\hline 17 & 55 & $\mathrm{~F}$ & - & Y & - & LE & $230 P$ & 6 & 6 & 2.4 & TINOMO \\
\hline 18 & 68 & $\mathrm{~F}$ & - & - & - & LE & 9EP & 10 & 10 & 5.4 & T2NOMO \\
\hline 19 & 86 & $\mathrm{~F}$ & Y & Y & ARMD & RE & 730ЕР & 12 & 13 & 5.4 & T2NOMO \\
\hline 20 & 85 & $\mathrm{~F}$ & - & - & Glaucoma & $\mathrm{LE}$ & 130EP & 8 & 10 & 2.4 & T2NOMO \\
\hline 21 & 86 & $\mathrm{~F}$ & - & - & - & RE & 9EP & 9 & 10 & 2.7 & T2NOMO \\
\hline 22 & 71 & $\mathrm{~F}$ & - & - & - & RE & 1030ЕР & 8 & 9 & 2.4 & TINOMO \\
\hline 23 & 87 & $\mathrm{~F}$ & - & Y & - & LE & $11 \mathrm{PE}$ & 6 & 8 & 3.2 & TINOMO \\
\hline 24 & 59 & $\mathrm{~F}$ & - & - & - & LE & 230EP & 8 & 10 & 3 & T2NOMO \\
\hline 25 & 62 & $\mathrm{~F}$ & - & Y & - & LE & 9EP & 10 & 10 & 3.5 & T2NOMO \\
\hline 26 & 83 & $\mathrm{~F}$ & - & - & - & LE & 430ЕР & 9 & 9 & 2.9 & TINOMO \\
\hline 27 & 59 & M & - & - & - & LE & 4EP & 10 & 12 & 2.7 & T2NOMO \\
\hline 28 & 87 & $\mathrm{~F}$ & Y & Y & BDR & RE & 430ЕP & 10 & 10 & 2.7 & T2NOMO \\
\hline 29 & 82 & $\mathrm{~F}$ & - & Y & Glaucoma & LE & 3EP & 6 & 6 & 3.5 & TINOMO \\
\hline 30 & 84 & M & - & - & ARMD & LE & 3EP & 8 & 8 & 3.2 & TINOMO \\
\hline 31 & 82 & M & - & - & ARMD & LE & 430ЕР & 9 & 12 & 3.4 & T2NOMO \\
\hline 32 & 66 & $\mathrm{~F}$ & - & Y & - & RE & 9EP & 10 & 14 & 4.4 & T2NOMO \\
\hline 33 & 70 & M & - & - & - & $\mathrm{RE}$ & 10EP & 10 & 10 & 2.9 & T2NOMO \\
\hline 34 & 55 & M & - & - & - & RE & $5 P$ & 7 & 8 & 5 & TINOMO \\
\hline 35 & 82 & $\mathrm{~F}$ & $Y$ & Y & - & $\mathrm{LE}$ & 230EP & 12 & 10 & 3.4 & T2NOMO \\
\hline 36 & 68 & $\mathrm{~F}$ & - & - & - & RE & 6PE & 14 & 12 & 5.8 & T2NOMO \\
\hline 37 & 59 & M & - & Y & - & $\mathrm{RE}$ & $11 \mathrm{P}$ & 8 & 8 & 2.4 & TINOMO \\
\hline 38 & 87 & M & - & Y & - & $\mathrm{RE}$ & 9EP & 10 & 10 & 4.7 & T2NOMO \\
\hline 39 & 73 & $\mathrm{~F}$ & Y & Y & - & RE & 3EP & 12 & 12 & 3.4 & T2NOMO \\
\hline 40 & 54 & M & - & - & - & $\mathrm{RE}$ & 9EP & 5 & 7 & 2.4 & TINOMO \\
\hline 41 & 66 & M & - & - & ARMD & RE & $4 \mathrm{PE}$ & 9 & 9 & 3.7 & TINOMO \\
\hline 42 & 86 & $\mathrm{~F}$ & - & - & - & LE & $9 \mathrm{P}$ & 7 & 8 & 3.2 & TINOMO \\
\hline 43 & 79 & M & - & - & Glaucoma & LE & 130EP & 9.9 & 10 & 2.9 & T2NOMO \\
\hline 44 & 94 & $\mathrm{~F}$ & Y & Y & - & $\mathrm{LE}$ & 3EP & 10 & 10 & 2.4 & TINOMO \\
\hline 45 & 79 & $\mathrm{~F}$ & - & - & - & $\mathrm{LE}$ & 430EP & 10 & 10 & 2.7 & T2NOMO \\
\hline Prophylactic & group & & & & & & & & & & \\
\hline 1 & 53 & $\mathrm{~F}$ & - & - & - & RE & 1030ЕР & 10 & 16 & 4 & T2NOMO \\
\hline 2 & 66 & M & - & - & - & LE & $2 E P$ & 9 & 9 & 2.4 & TINOMO \\
\hline 3 & 78 & $\mathrm{~F}$ & - & - & - & $\mathrm{LE}$ & 9EP & 10.5 & 8 & 3 & T2NOMO \\
\hline 4 & 31 & M & - & - & - & $\mathrm{LE}$ & $\mathrm{IP}$ & 9 & 10 & 3.6 & T2NOMO \\
\hline 5 & 82 & $\mathrm{~F}$ & - & Y & - & $\mathrm{RE}$ & $6 \mathrm{E}$ & 12 & 13 & 3.2 & T2NOMO \\
\hline 6 & 51 & M & - & - & - & $\mathrm{RE}$ & $12 \mathrm{P}$ & 4 & 6 & 2.2 & TINOMO \\
\hline 7 & 59 & $\mathrm{~F}$ & - & - & - & $\mathrm{LE}$ & 2EP & 11 & 13 & 3.6 & T2NOMO \\
\hline 8 & 83 & $\mathrm{~F}$ & - & - & Glaucoma & LE & 2EP & 9 & 11 & 2.7 & T2NOMO \\
\hline 9 & 70 & M & Y & - & - & LE & $9 \mathrm{E}$ & 12 & 16 & 4.9 & T2NOMO \\
\hline 10 & 77 & $\mathrm{~F}$ & - & - & Glaucoma & RE & 1030EP & 6 & 7 & 2.5 & TINOMO \\
\hline 11 & 67 & $\mathrm{~F}$ & - & - & ARMD & RE & $3 \mathrm{PE}$ & 7 & 8 & 2 & TINOMO \\
\hline 12 & 68 & M & - & - & - & LE & 5EP & 9 & 10 & 3.6 & T2NOMO \\
\hline 13 & 47 & M & - & - & Glaucoma/BRVO & $\mathrm{RE}$ & 3PE & 6 & 7 & 2.7 & TINOMO \\
\hline 14 & 86 & $\mathrm{~F}$ & - & Y & ARMD & RE & 730EP & 7 & 10 & 2.4 & TINOMO \\
\hline 15 & 87 & M & - & Y & Glaucoma & RE & $9 \mathrm{P}$ & 8 & 8 & 2.8 & TINOMO \\
\hline 16 & 82 & $\mathrm{~F}$ & Y & Y & BDR & RE & 1030EP & 11 & 11 & 2.6 & T2NOMO \\
\hline
\end{tabular}

these observations, an additional group of 16 consecutive "high risk" (posterior tumours) eyes were given prophylactic laser treatment to prevent radiation retinopathy or maculopathy (table 3). No other factors other than those mentioned above and the patient's willingness to be treated influenced their inclusion in this group. This second group's mean follow up (since plaque treatment) was 23.2 months (table 4). Laser treatment required a mean 1.5 sessions and their follow up (since laser) has averaged 16.5 months. To date, three eyes
(19\%) have developed radiation retinopathy at 13,18 , and 21 months after laser (table 4).

\section{Clinical evaluations}

A complete eye examination, history and COMS (Collaborative Ocular Melanoma Study) type visual acuity determinations were performed. Standardised refractions were performed in COMS approved examination rooms with regulated lighting and backlit ETDRS (Early Treatment 


\begin{tabular}{|c|c|c|c|c|c|c|}
\hline \multirow{2}{*}{$\begin{array}{l}\text { Patients } \\
\text { Laser group }\end{array}$} & \multirow{2}{*}{$\begin{array}{l}\text { Plaque size } \\
\text { (mm) }\end{array}$} & \multirow{2}{*}{$\begin{array}{l}\text { Distance to } \\
\text { fovea }(\mathrm{mm})\end{array}$} & \multirow{2}{*}{$\begin{array}{l}\text { Distance to } \\
\text { optic nerve } \\
\text { (mm) }\end{array}$} & \multicolumn{3}{|c|}{ Dose (Gy) } \\
\hline & & & & Fovea & Optic nerve & Apex \\
\hline \multicolumn{7}{|c|}{ With retinopathy } \\
\hline 1 & 16 & 7.5 & 4.5 & 12.7 & 31.9 & 72.3 \\
\hline 2 & 14 & 8 & 9 & 23.4 & 17.0 & 80.0 \\
\hline 3 & 16 & 0 & 3.5 & 117.0 & 34.5 & 70.0 \\
\hline 4 & 16 & 5 & 8 & 45.3 & 17.7 & 76.6 \\
\hline 5 & 12 & 8 & 5 & 11.5 & 22.4 & 73.4 \\
\hline 6 & 16 & 1 & 4.5 & 215.3 & 65.1 & 81.0 \\
\hline 7 & 18 & 1 & 2 & 121.2 & 86.8 & 72.6 \\
\hline 8 & 16 & 8 & 6 & 29.4 & 66.8 & 80.0 \\
\hline 9 & 16 & 2 & 3.5 & 141.6 & 59.8 & 80.0 \\
\hline 10 & 16 & 2.5 & 2 & 62.4 & 39.7 & 70.6 \\
\hline 11 & 12 & 4.5 & 3 & 48.5 & 78.0 & 100.0 \\
\hline 12 & 20 & 8 & 12 & 17.4 & 4.2 & 71.0 \\
\hline 13 & 20 & 6 & 3 & 24.7 & 39.7 & 75.2 \\
\hline 14 & 14 & 1.5 & 4.2 & 71.1 & 27.9 & 70.0 \\
\hline 15 & 14 & 2.5 & 0 & 271.8 & 104.0 & 86.0 \\
\hline 16 & 14 & 4.5 & 0 & 86.8 & 148.6 & 87.8 \\
\hline 17 & 12 & 0.5 & 1 & 160.7 & 68.8 & 100.0 \\
\hline 18 & 14 & 7 & 10 & 7.6 & 12.3 & 80.1 \\
\hline 19 & 18 & 3 & 7 & 18.3 & 21.1 & 75.9 \\
\hline 20 & 14 & 3 & 5 & 33.7 & 17.8 & 80.0 \\
\hline 21 & 14 & 3 & 5 & 66.8 & 24.4 & 80.0 \\
\hline 22 & 14 & 0.5 & 4 & 113.9 & 25.6 & 69.0 \\
\hline 23 & 14 & 6 & 1.5 & 45.0 & 69.0 & 80.0 \\
\hline 24 & 14 & 2.5 & 3.5 & 55.7 & 38.5 & 69.7 \\
\hline 25 & 14 & 4.5 & 1.5 & 32.6 & 63.3 & 70.0 \\
\hline 26 & 14 & 0 & 1.1 & 199.0 & 53.3 & 80.0 \\
\hline 27 & 16 & 1 & 4 & 106.4 & 26.8 & 89.7 \\
\hline 28 & 14 & 8 & 6 & 19.8 & 32.8 & 80.0 \\
\hline 29 & 14 & 0 & 3.4 & 254.0 & 86.9 & 77.0 \\
\hline 30 & 12 & 3 & 6.4 & 88.7 & 28.1 & 90.0 \\
\hline 31 & 16 & 10 & 14 & 7.3 & 4.1 & 70.5 \\
\hline 32 & 18 & 1.5 & 6 & 74.1 & 20.9 & 79.5 \\
\hline 33 & 14 & 1 & 4 & 94.4 & 30.4 & 80.5 \\
\hline 34 & 16 & 2.75 & 0 & 139.1 & 182.6 & 67.1 \\
\hline 35 & 12 & 1 & 3 & 148.6 & 44.6 & 80.0 \\
\hline 36 & 18 & 3 & 0 & 20.5 & 15.6 & 74.6 \\
\hline 37 & 12 & 0 & 0 & 124.3 & 102.9 & 80.2 \\
\hline 38 & 16 & 3 & 6.5 & 76.9 & 26.7 & 80.1 \\
\hline 39 & 14 & 6.4 & 3 & 19.3 & 44.2 & 80.0 \\
\hline 40 & 12 & 3 & 6 & 39.6 & 17.1 & 70.0 \\
\hline 41 & 14 & 4.5 & 2.0 & 37.4 & 109.9 & 69.7 \\
\hline 42 & 16 & 4 & 0 & 27.3 & 79.9 & 66.0 \\
\hline 43 & 14 & 7 & 5 & 15.7 & 20.6 & 76.7 \\
\hline 44 & 14 & 0 & 3.6 & 223.0 & 64.7 & 80.0 \\
\hline 45 & 14 & 6 & 7.5 & 33.1 & 19.0 & 80.0 \\
\hline \multicolumn{7}{|c|}{ Prophylactic group } \\
\hline 1 & 14 & 2 & 4 & 80.3 & 36.6 & 78.3 \\
\hline 2 & 14 & 2.5 & 4.5 & 50.0 & 22.7 & 74.4 \\
\hline 3 & 16 & 4.4 & 1 & 33.2 & 67.1 & 73.6 \\
\hline 4 & 14 & 2 & 0 & 49.0 & 72.8 & 73.3 \\
\hline 5 & 18 & 6.5 & 5 & 15.7 & 23.6 & 75.0 \\
\hline 6 & 12 & 3 & 0 & 84.3 & 357.1 & 75.7 \\
\hline 7 & 18 & 0.5 & 1 & 31.8 & 21.5 & 75.0 \\
\hline 8 & 16 & 6 & 8 & 19.4 & 12.2 & 75.5 \\
\hline 9 & 20 & 10 & 6 & 10.8 & 16.3 & 68.7 \\
\hline 10 & 12 & 1.5 & 4.5 & 93.3 & 28.9 & 72.9 \\
\hline 11 & 12 & 5.5 & 2 & 19.1 & 44.4 & 77.1 \\
\hline 12 & 14 & 6 & 5 & 23.8 & 29.2 & 77.4 \\
\hline 13 & 12 & 4 & 0 & 34.8 & 104.1 & 77.6 \\
\hline 14 & 14 & 4 & 5 & 31.8 & 17.4 & 74.0 \\
\hline 15 & 12 & 5 & 8.4 & 24.1 & 55.8 & 75.0 \\
\hline 16 & 16 & 2.5 & 5 & 48.2 & 19.9 & 76.1 \\
\hline
\end{tabular}

Diabetic Retinopathy Study) charts. The tumor's basal dimensions were determined by ophthalmoscopy (direct, indirect, and contact lens techniques as needed), fluorescein angiography, 2D and 3D B-scan ultrasonography (table 1). ${ }^{13} 14$ Fundus photography and fluorescein angiography were used to evaluate changes in tumour circulation, for chorioretinal leakage, intraretinal microangiopathy, retinal neovascularisation, retinal haemorrhage, capillary dropout, and cystoid macular oedema. Patients were re-evaluated at every 46 month intervals after plaque radiation therapy.
Angiography was employed on a yearly basis or earlier if any signs or symptoms of radiation retinopathy were noted on clinical examination.

\section{Radiation treatment}

Our methods of plaque radiation therapy have been described. ${ }^{6}{ }^{14-17}$ In sum, palladium-103 seeds $\left({ }^{103} \mathrm{Pd}\right)$ were available at strengths of up to $5 \mathrm{mCi} / \mathrm{seed}$ (Theragenics Corp, Buford, GA, USA) and affixed into gold COMS-type eye plaques (Trachsel Dental Studio Inc. Rochester, MN, USA) 


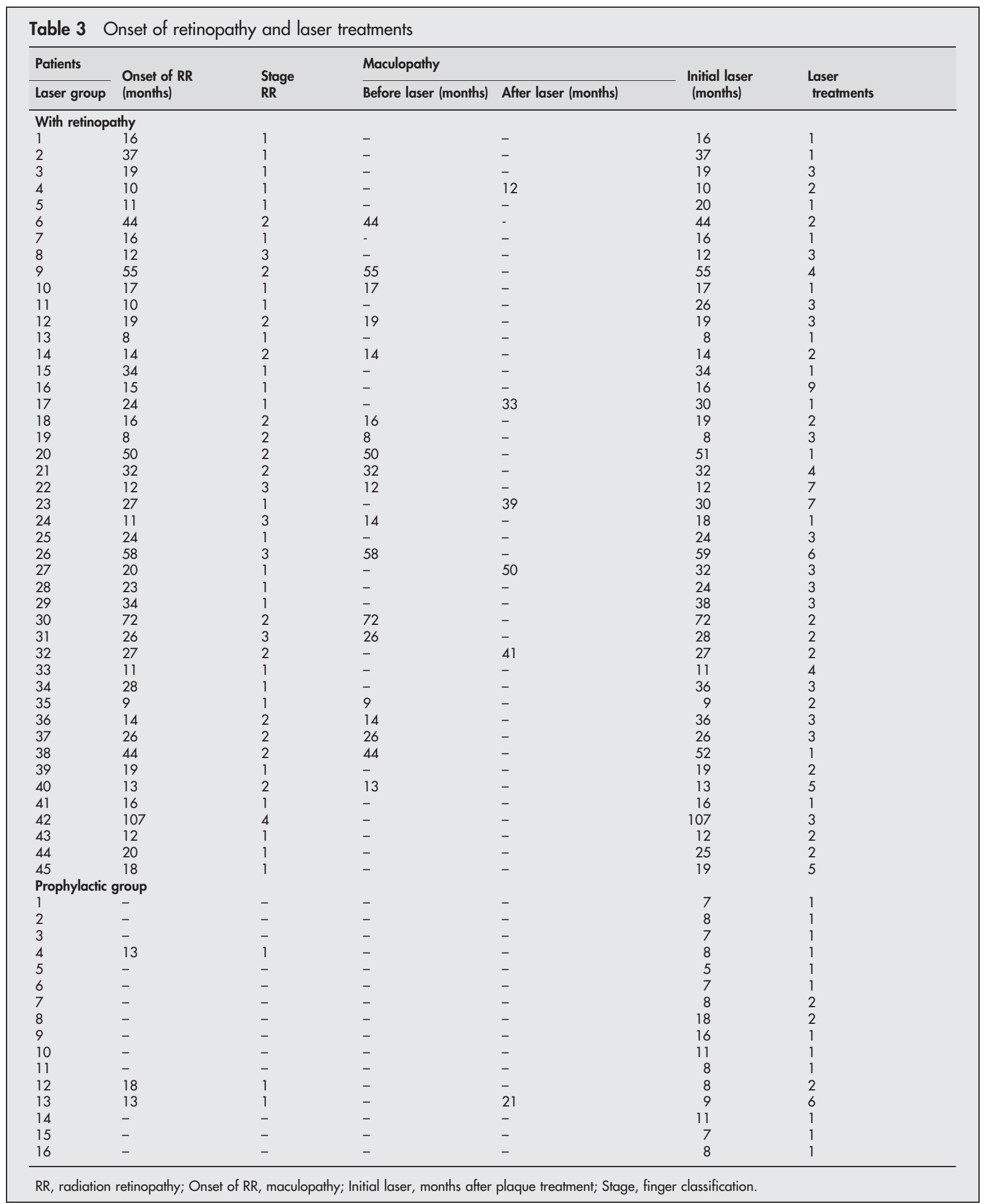

with a thin layer of acrylic fixative (table 2). Our dosimetric calculations, techniques of tumour localisation and episcleral plaque insertion have been described. ${ }^{61718}$ All patients received one brachytherapy treatment. Plaque brachytherapy started at insertion and continued until the prescribed dose was delivered (table 2). We used the COMS suggested apical dose rates of 50-125 cGy/h. Unlike COMS, but as consistent with the current recommendations of the American Brachytherapy Society, the prescription point was always the tumour's apex. ${ }^{6}{ }^{18}$ The mean apex dose (in this series) was 77 Gy (table 2).

\section{Radiation vasculopathy}

Closure of blood vessels is one of the central effects of ionising radiation. This characteristic has been exploited in the treatment of cancer and vascular disease. ${ }^{19}$

The histopathology of radiation induced ischaemic vasculopathy reveals the destruction of the endothelial cells and 


\begin{tabular}{|c|c|c|c|c|c|c|c|c|}
\hline \multirow{2}{*}{$\frac{\text { Patients }}{\text { Laser group }}$} & \multicolumn{2}{|c|}{ Regression } & \multirow{2}{*}{$\begin{array}{l}\text { Persistent RR } \\
\text { Post-laser }\end{array}$} & \multirow{2}{*}{$\frac{\text { New RR }}{\text { Post-laser }}$} & \multicolumn{2}{|c|}{ Visual acuity } & \multicolumn{2}{|c|}{ Follow up (months) afte } \\
\hline & RR & Maculopathy & & & Pre-laser & Recent & 1st laser & plaque \\
\hline \multicolumn{9}{|c|}{ With retinopathy } \\
\hline 1 & 16 & - & - & - & 20 & 20 & 23 & 49 \\
\hline 2 & 2 & - & - & - & 25 & 20 & 37 & 72 \\
\hline 3 & 12 & - & - & - & 250 & 400 & 43 & 59 \\
\hline 4 & 17 & 17 & - & - & 20 & 63 & 18 & 26 \\
\hline 5 & 1 & - & - & - & 20 & 16 & 1 & 19 \\
\hline 6 & 42 & 42 & - & - & 100 & 160 & 99 & 141 \\
\hline 7 & 4 & - & - & - & 32 & 32 & 7 & 20 \\
\hline 8 & 27 & - & - & - & 25 & 800 & 38 & 48 \\
\hline 9 & - & - & $\mathrm{Y}$ & - & 50 & 250 & 93 & 128 \\
\hline 10 & - & - & $Y$ & - & 32 & 32 & 36 & 52 \\
\hline 11 & 52 & - & - & - & 20 & 20 & 54 & 78 \\
\hline 12 & 22 & 22 & - & - & 40 & 25 & 44 & 58 \\
\hline 13 & 12 & - & - & - & 25 & 20 & 15 & 20 \\
\hline 14 & 28 & 28 & - & - & 20 & 250 & 34 & 54 \\
\hline 15 & - & - & $Y$ & - & 20 & 20 & 3 & 37 \\
\hline 16 & 8 & - & - & - & 30 & 200 & 51 & 66 \\
\hline 17 & 41 & 41 & - & - & 125 & $\mathrm{FC}$ & 72 & 98 \\
\hline 18 & - & - & $Y$ & - & 250 & 400 & 69 & 88 \\
\hline 19 & - & - & $Y$ & - & 160 & FC & 12 & 19 \\
\hline 20 & - & - & - & $Y$ & 25 & 125 & 33 & 80 \\
\hline 21 & - & - & - & $Y$ & 50 & FC & 64 & 92 \\
\hline 22 & 41 & 41 & - & - & 20 & 100 & 43 & 57 \\
\hline 23 & - & - & $Y$ & - & 125 & 400 & 105 & 132 \\
\hline 24 & 23 & 23 & - & - & 20 & 25 & 27 & 37 \\
\hline 25 & 29 & - & - & - & 20 & 20 & 29 & 51 \\
\hline 26 & 64 & 64 & - & - & 100 & 160 & 85 & 142 \\
\hline 27 & 66 & 66 & - & - & 400 & 200 & 85 & 116 \\
\hline 28 & - & - & - & $Y$ & 63 & 80 & 60 & 84 \\
\hline 29 & 106 & - & - & - & 80 & FC & 121 & 154 \\
\hline 30 & 33 & 33 & - & - & 250 & FC & 50 & 123 \\
\hline 31 & - & - & - & $Y$ & 63 & 160 & 21 & 47 \\
\hline 32 & - & - & $Y$ & - & 100 & $H M$ & 108 & 132 \\
\hline 33 & - & - & $Y$ & - & 30 & FC & 67 & 78 \\
\hline 34 & 2 & - & - & - & 25 & 125 & 11 & 45 \\
\hline 35 & - & - & - & $Y$ & 100 & NLP & 78 & 85 \\
\hline 36 & - & - & - & $Y$ & 50 & 150 & 0.5 & 36 \\
\hline 37 & 13 & 13 & - & - & 40 & 25 & 61 & 85 \\
\hline 38 & - & - & - & $Y$ & 100 & 80 & 23 & 54 \\
\hline 39 & 47 & - & - & - & 20 & 25 & 50 & 68 \\
\hline 40 & 43 & 43 & - & - & 20 & 80 & 46 & 56 \\
\hline 41 & 16 & - & - & - & 20 & 20 & 25 & 37 \\
\hline 42 & 15 & - & - & - & 63 & 32 & 48 & 152 \\
\hline 43 & - & - & - & $Y$ & 20 & 125 & 7 & 17 \\
\hline 44 & 8 & - & - & - & 40 & 50 & 74 & 98 \\
\hline 45 & 19 & - & - & - & 25 & 32 & 78 & 84 \\
\hline \multicolumn{9}{|c|}{ Prophylactic group } \\
\hline 1 & - & - & - & - & 20 & 20 & 14 & 21 \\
\hline 2 & - & - & - & - & 40 & 40 & 22 & 29 \\
\hline 3 & - & - & - & - & 20 & 20 & 0.25 & 7 \\
\hline 4 & 10 & - & - & - & 32 & 20 & 18 & 24 \\
\hline 5 & - & - & - & - & 20 & 20 & 14 & 17 \\
\hline 6 & - & - & - & - & 32 & 32 & 3 & 9 \\
\hline 7 & - & - & - & - & 20 & $\mathrm{HM}$ & 32 & 40 \\
\hline 8 & - & - & - & - & 25 & 25 & 19 & 29 \\
\hline 9 & - & - & - & - & 25 & 20 & 47 & 53 \\
\hline 10 & - & - & - & - & 25 & 20 & 10 & 19 \\
\hline 11 & - & - & - & - & 40 & 40 & 0.5 & 8 \\
\hline 12 & 14 & - & - & - & 20 & 20 & 18 & 29 \\
\hline 13 & 24 & 24 & - & - & 16 & 32 & 29 & 36 \\
\hline 14 & - & - & - & - & 40 & 50 & 19 & 24 \\
\hline 15 & - & - & - & - & 40 & 40 & 1 & 6 \\
\hline 16 & - & - & - & - & 20 & 20 & 18 & 21 \\
\hline
\end{tabular}

RR, radiation retinopathy; Stage, finger classification; Regression, months after laser; FC, finger counting; HM, hand motion; NLP, no light perception.

pericytes that maintain blood vessel walls. ${ }^{19}$ Microaneurysms develop in acellular and poorly supported capillaries. These changes alter blood flow patterns and produce alternative channels with thickened and fenestrated walls. ${ }^{19}$ This effect is dependent on the mitotic activity of the irradiated cells and the radiation dose over time. It is no surprise that one of the most common fluorescein findings after radiation therapy of choroidal melanomas is closure of blood vessels within and around the tumour. This effect is seen to a lesser degree (at a lower dose) in the tissues surrounding the targeted zone.

\section{Finger classification of radiation retinopathy}

Owing to the lack of a prognosis related classification for radiation retinopathy, and the need for a common language for comparative studies, this study prompted the creation of the classification presented in table $5 .{ }^{20}$ There are certain preproliferative findings associated with radiation treatment of the eye. ${ }^{41}$ Ophthalmoscopy is best used to view such common findings as cotton wool spots, retinal haemorrhages, ghost vessels, exudates and the less frequent retinal microaneurysms and uveal effusions. Fluorescein and indocyanine 
Table 5 Finger classification of radiation retinopathy

\begin{tabular}{|c|c|c|c|c|c|}
\hline Stage & Sign & Symptom & Location & Best viewed by & Risk of vision loss \\
\hline 1 & $\begin{array}{l}\text { Cottonwool spots } \\
\text { Retinal haemorrhages } \\
\text { Retinal micro-aneurysms } \\
\text { Ghost vessels } \\
\text { Exudate } \\
\text { Uveal effusion } \\
\text { Chorioretinal atrophy } \\
\text { Choroidopathy } \\
\text { Retinal ischaemia (<5 DA) }\end{array}$ & $\begin{array}{l}\text { None } \\
\text { None } \\
\text { None } \\
\text { None } \\
\text { None } \\
\text { None } \\
\text { None } \\
\text { None } \\
\text { None }\end{array}$ & $\begin{array}{l}\text { Extramacular } \\
\text { Extramacular } \\
\text { Extramacular } \\
\text { Extramacular } \\
\text { Extramacular } \\
\text { Extramacular } \\
\text { Extramacular } \\
\text { Extramacular } \\
\text { Extramacular }\end{array}$ & $\begin{array}{l}\text { Ophthalmoscopy } \\
\text { Ophthalmoscopy } \\
\text { Ophthalmoscopy } \\
\text { Ophthalmoscopy } \\
\text { Ophthalmoscopy } \\
\text { Ophthalmoscopy } \\
\text { Ophthalmoscopy } \\
\text { Angiography } \\
\text { Angiography }\end{array}$ & $\begin{array}{l}\text { Mild } \\
\text { Mild } \\
\text { Mild } \\
\text { Mild } \\
\text { Mild } \\
\text { Mild } \\
\text { Mild } \\
\text { Mild } \\
\text { Mild }\end{array}$ \\
\hline \multirow[t]{2}{*}{3} & $\begin{array}{l}\text { Above findings } \\
\text { Any combination of the above plus }\end{array}$ & None & Macular & Both & Moderate \\
\hline & $\begin{array}{l}\text { Retinal neovascularisation } \\
\text { Macular oedema-new onset }\end{array}$ & $\begin{array}{l}\text { Vision loss } \\
\text { Vision loss }\end{array}$ & $\begin{array}{l}\text { Extramacular } \\
\text { Macular }\end{array}$ & $\begin{array}{l}\text { Angiography } \\
\text { Angiography }\end{array}$ & $\begin{array}{l}\text { Severe } \\
\text { Severe }\end{array}$ \\
\hline \multirow[t]{3}{*}{4} & Any combination of the above plus & & & & \\
\hline & Vitreous haemorrhage & Vision loss & Vitreous & Ophthalmoscopy & Severe \\
\hline & Retinal ischaemia ( $>$ or $=5 \mathrm{DA}$ ) & Vision loss & $\begin{array}{l}\text { Extramacular and } \\
\text { macular }\end{array}$ & Angiography & Severe \\
\hline
\end{tabular}

green angiography are typically used to define the extent of retinal ischaemia and vascular anomalies (table 5).22 23

When located outside the macula, stage 1 findings are consistent with excellent central vision and a good visual prognosis (mild risk). In contrast, stage 2 radiation retinopathy requires that these pathological findings are located in the macula and therefore carry a more guarded prognosis for vision (moderate risk).

When the eye enters stage 3, some vision loss has probably occurred and the prognosis for return to pretreatment vision is poor (severe risk). Despite its location, the presence of retinal neovascularisation is ominous. It suggests a profound ischaemic drive and carries a worse prognosis for long term visual acuity (table 5). Vitreous haemorrhage, large areas of retinal ischaemia, and iris neovascularisation are associated with a worse prognosis for vision and globe salvage (table 5). Vitreous haemorrhage clouds our ability to use laser treatment and to monitor the progression of radiation retinopathy. Patients who present with vitreous haemorrhage often have occult neovascularisation and are at risk for ghost cell or neovascular glaucoma. ${ }^{24}$

\section{Radiation retinopathy and regression}

Radiation retinopathy was treated based on the appearance of any of the following stage 1 findings: retinal haemorrhages, cottonwool spots, intraretinal microangiopathy, exudation, choroidopathy (as seen on angiography), retinal ischaemia (seen clinically or on the angiogram) or other ischaemic changes such as neovascularisation of the iris or retina as seen in the later stages (table 5). Radiation maculopathy was defined as when one or more of these findings were found to affect the macular retina. ${ }^{421}$ Patients in this series were staged as their retinopathy appeared before their first laser treatment.

Regression of radiation retinopathy was defined as the disappearance or regression of the above findings. Patients who were noted to have regression did not progress to stages 2 to 4 within the follow up duration of this study.

\section{Laser photocoagulation}

Plaque radiation therapy creates a zone of ischaemia within and immediately surrounding the targeted zone (beneath the plaque). As the prescribed radiation dose increases, so does the area of surrounding ischaemic tissue. In a first study, it seemed most reasonable to treat the targeted tissue that was located beneath the plaque during radiation therapy. Therefore, a sector of argon laser photocoagulation was typically placed over the tumour surface and a surround of 2-3 $\mathrm{mm}$. This initial pattern of laser was distributed within the area of choroid, retina, and tumour that was directly beneath the plaque during brachytherapy. As needed, this area was enlarged as to include new areas of intraretinal microangiopathy and retinal neovascularisation as demonstrated on fluorescein angiography. Typical laser settings included a $200 \mu \mathrm{m}$ spot size, $0.1-0.2 \mathrm{~ms}$ duration, and 100$300 \mathrm{~mW}$. The number of spots depended on the size of the tumour. A tight pattern of scatter laser photocoagulation was employed. Care was taken to avoid photocoagulation of the fovea or optic nerve.

\section{RESULTS}

\section{Control of radiation retinopathy}

Sector argon laser photocoagulation performed after the first sign of radiation retinopathy resulted in regression in 29 $(64.4 \%)$ of the 45 patients with retinopathy before laser (fig 1). In this group, $19(42.2 \%)$ of the 45 patients presented with radiation maculopathy before laser. Only five (19.2\%) of the 26 patients with extramacular retinopathy progressed to macular involvement despite laser treatment. Nine $(47.4 \%)$ of the 19 macular retinopathies at the time of initial laser were found to regress (table 4).

Laser treatment was considered to be a failure if the retinopathy persisted or new ischaemic changes developed. Of the 16 patients in whom the retinopathy did not regress after laser, eight had persistence of their retinopathy and eight had development of new retinal findings (cystoid macular oedema $(n=4)$, new neovascularisation $(n=3)$ and iris neovascularisation $(\mathrm{n}=1))$.

\section{Prevention of radiation retinopathy}

Of the 16 high risk patients treated before onset of clinically detectable radiation retinopathy, one developed radiation maculopathy and two had radiation retinopathy outside the macula (table 3 ). In all three cases additional photocoagulation was added which enlarged the sector of treatment and resulted in regression of the radiation retinopathy (fig 2). No persistence of retinopathy or development of new ischaemic changes were seen.

\section{Vision results}

Radiation maculopathy was the most common cause of vision loss in this study. Of the 45 patients who received laser after the onset of radiation retinopathy, $21(46.7 \%)$ patients lost three or more lines of vision (table 4 ). In this group, the 

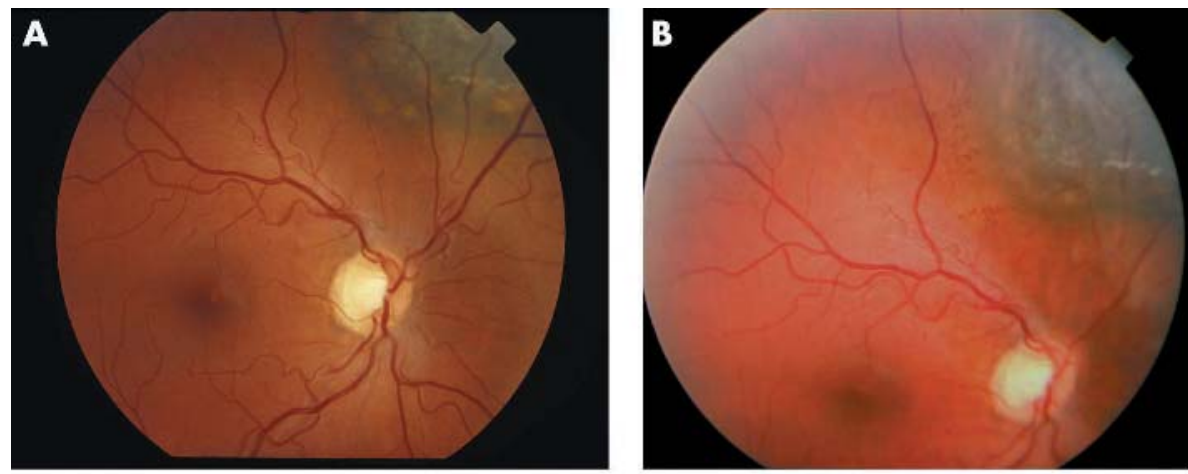

Figure 1 A composite photograph showing a pretreatment fundus photograph (A), and a photograph demonstrating radiation retinopathy at 24 months (B). A fluorescein angiogram demonstrates intraretinal microangiopathy next to the tumour (C), and regression to chorioretinal scar after laser photocoagulation (D).
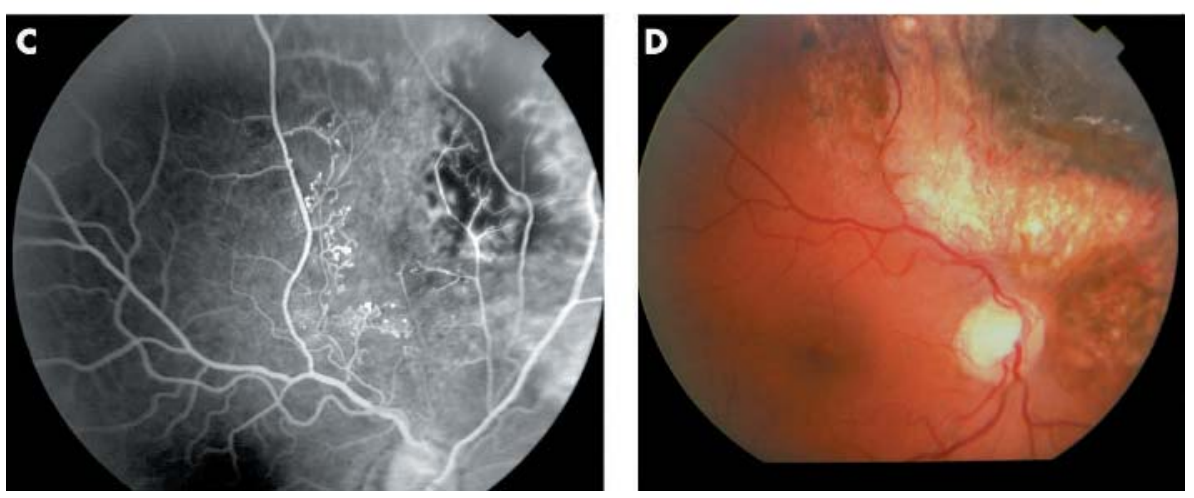

primary reason for vision loss was $(n=7)(33.7 \%)$ radiation maculopathy, $(\mathrm{n}=3)$ persistent exudative macular detachments, $(n=2)$ radiation optic neuropathy, $(n=2)$ vitreous haemorrhage, $(\mathrm{n}=2)$ macular degeneration, $(\mathrm{n}=2)$ diabetic maculopathy, $(\mathrm{n}=1)$ neovascular glaucoma, $(\mathrm{n}=1)$ macular pucker/cataract, and $(\mathrm{n}=1)$ retinal macroaneurysm with macular exudation. Of the five patients with radiation retinopathy who did not have laser, two lost more than three lines of vision and three have maintained stable acuities (table 4).

Of the 16 patients who received laser treatment before clinical evidence of retinopathy, one developed radiation
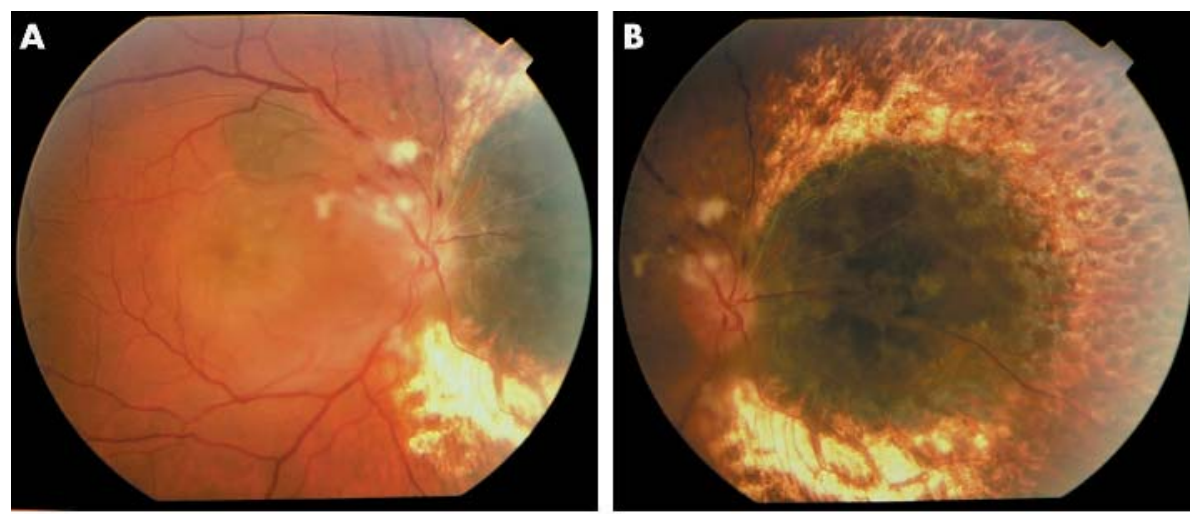

Figure 2 This patient received prophylactic laser on and around the tumour and went on to develop radiation retinopathy (A, B). His retinopathy regressed after additional extramacular laser photocoagulation resulting in resolution of his radiation maculopathy and most recently was found to maintain $20 / 25$ vision at 43 months follow up (C, D).
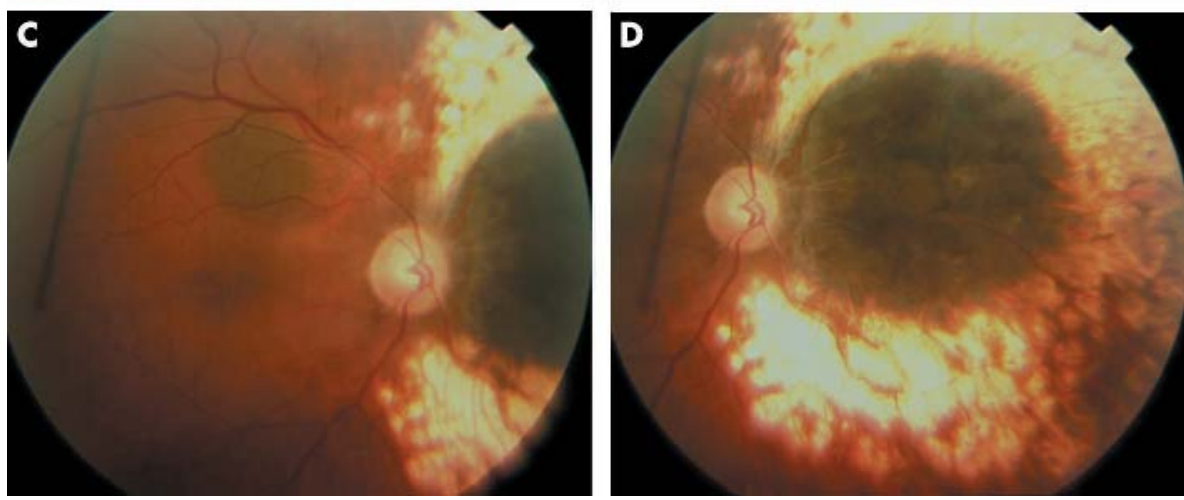
maculopathy and two developed retinopathy without maculopathy (all three responded to additional laser photocoagulation) (table 4). No patients in the prophylactic laser group lost more than three lines of vision as a result of maculopathy (table 4).

\section{Side effects of laser treatment}

Few side effects could be related to laser treatment. Patients were counselled that they might experience deepening or widening of their tumour related scotoma. Five experienced this symptom. They were also warned of possible secondary haemorrhages, cystoid macular oedema, and the chance of laser to the fovea, but none was noted.

\section{Statistical analysis}

We attempted to compare statistically the incidence of radiation retinopathy in the two groups involved in this study. But since we had selected patients found to have radiation retinopathy for inclusion in the first group $(n=45)$, we could not reasonably compare them to those just at risk $(n=16)$. The mean onset of retinopathy in the radiation retinopathy group was 26 months and the mean follow up in the prophylactic group was 23.2 months. The onset of retinopathy could not be statistically matched to the length of follow up in the prophylactic group for comparison.

\section{DISCUSSION}

Ophthalmic radiation therapy has been reported to cause cataract, scleral necrosis, radiation retinopathy, and optic neuropathy. ${ }^{2}$ Radiation dose is a dominant factor. It is clear that the use of larger radiation doses increases the incidence of radiation related complications and decreases the probability of repairing them (for example, with laser photocoagulation). ${ }^{2}{ }^{14}$

Cataract and radiation retinopathy are the most common vision limiting radiation associated complications seen after plaque treatment. ${ }^{212}$ Unlike radiation cataracts (that are amenable to surgical rehabilitation) radiation maculopathy has been the leading cause of permanent and severe vision loss. ${ }^{25}$ Clearly, a method to prevent or treat radiation maculopathy will decrease blindness associated with plaque radiation therapy.

Finger noted a close relation between the plaque/tumour position and the location of subsequent radiation oculopathy. ${ }^{12}$ Specifically, compared to $4 \%$ of patients with anterior uveal melanomas, $52 \%$ of patients $(\mathrm{p}<0.0001)$ with posterior choroidal melanoma developed retinopathy secondary to plaque brachytherapy in that series. ${ }^{12}$ Similarly, a separate study reported that of 1300 patients treated with plaque radiotherapy for posterior uveal melanomas, $42 \%$ developed radiation retinopathy at 5 years. ${ }^{5}$ Clearly, these studies define which patients are at greatest risk for radiation retinopathy and those who should be included in a preventative trial.

In this study, sector argon laser photocoagulation treatment regressed clinically evident radiation retinopathy in $64.4 \%$ patients with early onset retinopathy and 100\% of "breakthrough" patients treated before developing radiation retinopathy. These findings suggest that scatter argon laser photocoagulation of the radiation targeted zone is effective in preventing or regressing radiation retinopathy. They also suggest that intervention before clinically apparent radiation retinopathy may be more effective than treatment after its onset. Prevention of radiation retinopathy is particularly important when considering the radiation maculopathy patient. Here, prevention is much more likely to preserve vision than treatment after its onset.

Treatment of radiation retinopathy is a very important subject worthy of exposure, discussion, and attention within the ophthalmic community. Local tumour control rates after ophthalmic plaque radiation therapy are greater than $90 \%$ in most series; unfortunately vision retention rates after plaque radiation therapy are typically poor (typically 20/200 or less in these reports after 5 years). ${ }^{2625}$ It is reasonable to assume that plaque radiation related ischaemic oculopathy is similar to other regional ocular ischaemic processes (for example, branch vein occlusion). ${ }^{10}$ Therefore, it makes sense that laser ablation of the ischaemic zone may benefit long term vision retention.

This study suggests that sector scatter laser photocoagulation can be used to regress radiation retinopathy, preserve patient vision and ocular health. Despite these positive findings we believe that a controlled, randomised clinical trial should be performed to establish a statistically significant proof of benefit and to develop practice guidelines for the treatment of radiation retinopathy.

\section{ACKNOWLEDGEMENTS}

We thank Dr Goupei Yu from the New York Eye and Ear Infirmary, New York, for his help with the statistical analysis involved with this study. We also thank Dr Frederick, Boston, MA, USA, for sharing in patient care.

\section{Authors' affiliations}

P T Finger, New York Eye Cancer Center, The New York Eye and Ear Infirmary, and New York University School of Medicine, New York City, NY, USA

M Kurli, New York Eye Cancer Center, The New York Eye and Ear Infirmary, and New York University School of Medicine, NY, USA

This research was supported by The EyeCare Foundation, Inc and Research to Prevent Blindness, New York, USA

The authors have no proprietary interest in the technology mentioned in this study.

\section{REFERENCES}

1 Sagerman RH, Alberti WE. Radiotherapy of intraocular and orbital tumors. 2nd ed. Vol 1. Berlin, Heidelberg, New York: Springer, 2003:1-295.

2 Finger PT. Radiation therapy for choroidal melanoma. Surv Ophthalmol 1997:42:215-32

3 Sagerman RH, Alberti WE. Radiosensitivity of ocular and orbital structures. In: Sagerman RH, Alberti WE, eds. Radiotherapy of intraocular and orbital tumors. Berlin, Heidelberg, New York: Springer, 2003;2:269-80.

4 Guyer DR, Mukai S, Egan KM, et al. Radiation maculopathy after proton beam irradiation for choroidal melanoma. Ophthalmology 1992;99:1278-85.

5 Gunduz K, Shields CL, Shields JA, et al. Radiation retinopathy following plaque radiotherapy for posterior uveal melanoma. Arch Ophthalmol 1999; 117:609-14.

6 Finger PT, Berson A, $\mathrm{Ng} \mathrm{T}$, et al. Palladium-103 plaque radiotherapy for choroidal melanoma: an 11 -year study. Int J Radiat Oncol Biol Phys 2002; 54: 1438-45.

7 Melia BM, Abramson DH, Albert DM, et al. Collaborative ocular melanoma study (COMS) randomized trial of I-125 brachytherapy for medium choroidal melanoma. I. Visual acuity after 3 years COMS report no. 16. Ophthalmology $2001 ; 108: 348-66$

8 Chaudhuri PR, Austin DJ, Rosenthal AR. Treatment of radiation retinopathy Br J Ophthalmol 1981;65:623-5.

9 Augsburger JJ, Roth SE, Magargal LE, et al. Panretinal photocoagulation for radiation-induced ocular ischemia. Ophthalmic Surg 1987;18:589-93.

10 Branch Vein Occlusion Study Group. Argon laser scatter photocoagulation for prevention of neovascularization and vitreous hemorrhage in branch vein occlusion. A randomized clinical trial. Arch Ophthalmol 1986;104:34-41.

11 The COMS Study Group. Assessment of metastatic disease status at death in 435 patients with large choroidal melanoma in the Collaborative Ocular Melanoma Study (COMS): COMS report no. 15. Arch Ophthalmol $2001 ; 119: 670-6$.

12 Finger PT. Tumour location affects the incidence of cataract and retinopathy after ophthalmic plaque radiation therapy. $\mathrm{Br} J$ Ophthalmol 2000;84: 1068-70.

13 Romero JM, Finger PT, lezzi R, et al. Three-dimensional ultrasonography of choroidal melanoma: extrascleral extension. Am J Ophthalmol 1998; 126:842-4

14 Finger PT, Romero JM, Rosen RB, et al. Three-dimensional ultrasonography of choroidal melanoma: localization of radioactive eye plaques. Arch Ophthalmol 1998;1 16:305-12.

15 Finger PT, Moshfeghi DM, Ho TK. Palladium 103 ophthalmic plaque radiotherapy. Arch Ophthalmol 1991;109:1610-3. 
16 Finger PT, Lu D, Buffa A, et al. Palladium-103 versus iodine-125 for ophthalmic plaque radiotherapy. Int J Radiat Oncol Biol Phys 1993;27:849-54

17 Finger PT, Buffa A, Mishra S, et al. Palladium 103 plaque radiotherapy for uveal melanoma. Clinical experience. Ophthalmology 1994;101:256-63.

18 Nag S, Quivey JM, Earle JD, et al. The American Brachytherapy Society recommendations for brachytherapy of uveal melanomas. Int $J$ Radiat Oncol Biol Phys 2003;56:544-55.

19 Archer DB, Amoaku WM, Gardiner TA. Radiation retinopathy-clinical, histopathological, ultrastructural and experimental correlations. Eye 1991;5:239-51.

20 Finger PT. Guest editorial: Do you speak ocular tumor? Ophthalmology 2003;110:13-14.
21 Brown GC, Shields JA, Sanborn G, et al. Radiation retinopathy Ophthalmology 1982;89:1494-501.

22 Spaide RF, Borodoker N, Shah V. Atypical choroidal neovascularization in radiation retinopathy. Am J Ophthalmol 2002;133:709-11.

23 Spaide RF, Leys A, Hermann-Delamazure B, et al. Radiationassociated choroidal neovasculopathy. Ophthalmology 1999; 106:2254-60

24 Spraul CW, Grossniklaus HE. Vitreous hemorrhage. Surv Ophthalmol 1997:42:3-39.

25 Diener-West $M$, Earle JD, Fine SL, et al. The COMS randomized trial of iodine 125 brachytherapy for choroidal melanoma, III: initial mortality findings. COMS Report No 18. Arch Ophthalmol $2001 ; 119: 969-82$ 